\title{
An Open Source LMS, Vision, and Development. The Development of Innovative Web Technologies for E-Learning: The eLearning Portal Project
}

\author{
Agostino Marengo, Michele Baldassarre, \\ and Alessandro Pagano \\ University of Bari, Italy
}

amarengo@dss.uniba.it; uniba.it@gmail.com; aleko21@gmail.com

\begin{abstract}
The aim of the project is the development of an innovative, Open Source-based eLearning portal, which provides high scalability and versatility, as well as it is easy to upgrade; it aims at meeting some changeable requirement in the field of distance learning (yearly or even monthly innovation).

The modular structure and flexibility provided by the portal makes this system adaptable to any kind of educational and/or academic situation, allowing also the development in step with innovative and specific Web Technologies.

The project has been developed thanks to the experience obtained in managing a postgraduate specialization course promoted by University of Bari (www.comedudida.org) and it keeps developing as suitable tools for proper online formation are designed. This experience has been studied inside the OSEL research project by University of Bari (www.osel.it).
\end{abstract}

Keywords: LMS, e-learning, open-source, distance learning, web technologies.

\section{Introduction}

Updating ability and flexibility towards the necessity of implementing innovation into technology as well as educational and meta-cognitive methodologies were the basic criteria for choosing software which will be used for developing the portal.

A modular system will also allow managing questions not concerning the distance learning course, and it will update its framework, adding new features.

The innovative nature of this project will be also driving force the development of Mobile Learn-

Material published as part of this publication, either on-line or in print, is copyrighted by the Informing Science Institute. Permission to make digital or paper copy of part or all of these works for personal or classroom use is granted without fee provided that the copies are not made or distributed for profit or commercial advantage AND that copies 1) bear this notice in full and 2) give the full citation on the first page. It is permissible to abstract these works so long as credit is given. To copy in all other cases or to republish or to post on a server or to redistribute to lists requires specific permission and payment of a fee. Contact Publisher@InformingScience.org to request redistribution permission. ing, thanks to MobileED project.

Opportunities provided by Zope, Plone and Fle 3 will help the present project as far as the educational and technological side is concerned. Developing and planning new methods and modules will represent the future of the present research project.

The main aim of this project is the realization of an e-Learning portal with col- 
laborative organization of contents and with a section dedicated to collaborative distance learning. Integration between software and learning structure will improve portal features, and teaching/learning process. The aim of this project is the development of an innovative Open Source eLearning portal, with some distinctive features:

- Scalability

- High versatility

- Easy to upgrade

- Suitable for many environments

The portal will provide a collaborative managing contents structure, and social networking instruments for distance learning. In order to meet these basic topics, the project provides a modular system, looking towards mobile learning technologies, thanks to MobilED software. Developing and planning new methods and modules will represent the future of the present research project.

\section{Application Fields}

The possible scenarios of this flexible website are various: we can successfully manage a university department, or even e-Learning courses. It is possible to manage "virtual classes" or organize "workgroups" involving foreign students.

The possible scenarios are:

- Classrooms: fle3 is suitable for "virtual classrooms".

- Universities.

- Postgraduate specialization course: there is an actual example represented by comedudida.org. This experience has guided the research work in this project.

- Administration of entire university departments: thanks to the zope+plone structure, we are even able to manage many bureaucratic issues in a course.

- Blended learning project.

- Simplify collaboration in research groups.

- Build new collaborative structures: thanks to a collaborative learning approach, this portal is also suitable to build other collaborative-based activities.

- And so on... the extreme flexibility of this structure can adapt the platform according to specific needs.

\section{A Specific Situation}

The project has been developed thanks to the experience obtained in managing a postgraduate specialization course promoted by University of Bari (http://www.comedudida.org) and it keeps developing as suitable tools for proper online formation are designed. The study of this experience has been made during the OSEL (Open Source e-learning) Project (http://www.osel.it) conducted by the OSEL group, coordinated by Agostino Marengo (Marengo, Scalera, Convertini, \& Albanese, 2007)

The research group found that a specific PHP/Mysql platform, especially designed for the course, was too difficult to upgrade and too rigid to be managed and it is problematical to follow educational technologies innovations. 
The group needs a flexible structure in order to upgrade the course every year and add some new features, as well as we need powerful control in course activities, in order to follow students accurately.

The group needs to upgrade learning methodologies, improving collaborative technologies, and following the approach proposed by Web 2.0.

There is a well-established trend dealing with updating and improvement of teaching methodologies, using Web 2.0 tools.

The main aim is to apply the "e-Learning 2.0" concept with collaborative activities and tools created in order to "create knowledge", instead of using traditional tools.

This methodology focuses on collaborative activities, the latter meant as the basis of "knowledge creation".

Fle3 educational approach is based on a social-constructivist theory, giving prominence to experience-based learning.

Fle3 is considered as a single tool: it does not provide the "bureaucratic + back office" requirements of an online course. The structure provided by Zope + Plone allows administrators to manage different scenarios, such as an online secretariat both for a single course or an entire department. The structure of this portal allows the differentiation of specific roles for the secretarial staff, thus enabling managing functions for their organizational activity.

\section{Main Features and Software Tools}

A data-based management system (DBMS) provides users data storing, privileging the existing contents, and even the modification of each user on this contents. This is useful to preserve every version of didactical object, to do a "come back" to previous content status.

The flexible modular structure makes this system adaptable to many educational and/or academic situations.

Updating possibility and flexibility towards the necessity of implementing innovation into technology as well as educational and meta-cognitive methodologies were the basic criteria for choosing the software used to build and develop the portal.

The innovative nature of this project will also help the development of Mobile Learning, thanks to MobileED project.

The model focuses on student-centered collaborative activities aiming at producing knowledge and designing artifacts by embedding meaningful tools and involving the use of information and Communication Technology (network computers and mobile devices) in the learning process. The research group managed to apply the concept of "eLearning 2.0" with collaborative activities and tools designed to "create knowledge" instead of following the traditional learning method.

Fle3 is the acronym for "Future Learning Environment": the theoretical background of FLE is located in the social-constructivist theory, which considers learning as participation in social process of knowledge construction.

The group's attention is also focused towards bureaucratic issues, but FLE is not adequate to carry out this kind of activities. In this environment the group needs to streamline bureaucracy issues. The platform aims at solving some administrative problems that may be encountered throughout the course. The Zope+Plone structure provides a strong and flexible office and course administration solution with specific "office/staff-users" different from other roles (such as tutors or professors.) 


\section{Main Software Tools}

This portal project is based on Open Source software and tools:

- Linux Server (gentoo)

- Client (any OS) + Browser

- Zope

- Plone

- Fle3

- MobilED

Zope is an open source application server for building content management systems, intranets, portals, and custom applications.

The Zope community consists of hundreds of companies and thousands of developers all over the world, working on building the platform and Zope applications.

Zope is written in Python, a highly-productive, object-oriented scripting language.

Zope stands for "Z Object Publishing Environment". It can almost full manage with web-based user interface. Zope publishes on the web, python objects that are typically persisted in an object database called ZODB.

These objects could be documents, images, page templates, and so on... and are available to users to create and manage them trough the web.

Specialized object types, such as wikis, blogs, and photo galleries, are available as third-party add-ons (called products), and there is a thriving community of small businesses creating custom web applications as Zope products.

Plone is an open-source content management system/framework that works hand-in-hand and sits on top of Zope.

It is a free software and is designed to be extensible. It is suited for an internal website or may be used as a server on the Internet, playing such roles as a document publishing system and groupware collaboration tool.

Plone is written in Python. This programming language, can be used to add new features to Plone, and used to understand or make changes to the way that Zope and Plone work.

By default, Plone stores its contents in Zope's built in transactional object database, the ZODB. There are products and techniques, however, that share information with other sources, such as relational databases, LDAP, filesystem files, etc...

Several Products may be combined by Plone in order to provide additional functionality; these products are distributed through the Plone website or otherwise.

Plone's strong points are accessibility and multi-linguality. It's secure, but has heavy resource dependencies. Plone is noted as a good intranet software. It is suitable for high-load production internet sites using caching via Apache/Squid in front, combined with the CacheFu Plone product.

FLE is a web-based learning environment: a server software for computer supported collaborative learning.

Fle3 is a Zope product, written in Python. This project is an open source and free software released under the GNU General Public Licence (GPL). 
Fle3 user interface is translated into more than 20 languages including most of the European languages and Chinese. It is used in more than 70 countries.

Fle 3 is designed to support learner and groups centered work that concentrates on creating and developing expressions of knowledge (i.e. knowledge artifacts) and design, in fact it is focused on collaborative learning and teamwork.

With FLE instruments, it's possible to create virtual classes, giving them the possibility to create and develop knowledge artifacts and design.

The MobilED initiative is aimed at designing teaching and learning environments that are meaningfully enhanced with mobile technologies and services.

MobilED deliverables are to develop a set of scenarios and guidelines of how mobile technologies could be used for teaching, learning and empowerment of students within and outside the school context.

A set of concepts and prototypes that will be developed into a MobilED platform that facilitates and supports the scenarios and guidelines developed and testing, evaluation, dissemination and sustainability strategies for the MobilED platform in real contexts with real people.

MobilED Server is a set of mobile services targeted for mobile learners. In the first stage MobilED experimenting with SMS gateways, and wiki engine; but future developments also include moblogging (text, audio, images and video) or mobwiki (uploading audio, images and videos to Wiki), as well as knowledge building and problem solving tools and simulations.

\section{Software Structure}

As shown in Figure 1, the software structure is modular / onion-skin, in fact you can see that the core is the programming language (Python), so that we have Zope, which works as a strong and stable web server and then, at the upper level, we can find Plone and Fle3 which are the effective user interface.

\section{The Didactic Environment: FLE3}

To use Fle 3 you need a computer connected to a computer network. The network you will be using is most likely, the Internet. However, a connection to "public Internet" is not a requirement as it is possible to use Fle3 in a local area network or Intranet using the Internet pro-

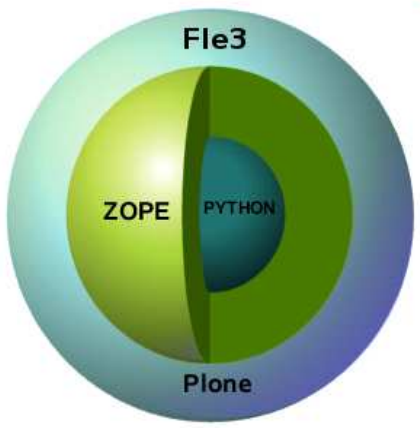

Figure 1: Onion Skin structure for the software. tocol. Contact your administration to establish the most suitable connection.

Fle3 works with every standard web-browser. In your web browser you just have to point to the location of your Fle 3 server installation and $\log$ in.

Fle3 contains three learning tools for collaborative learning and several administration tools.

Fle3 WebTop, as you can see in Figure 2, can be used by teachers and students to store different items (documents, files, links, knowledge building notes) related to their studies, organize them into folders and share them with other users. WebTop also includes a shared "course folder" for each course. The same shared "course folder" is available in the Knowledge Building and Jamming tools as well. The items in the WebTops can be called learning objects, the study of this 
kind of learning object has been made during the OSEL Project conducted by the OSEL group (Convertini, Albanese, Marengo, Marengo, \& Scalera, 2006).

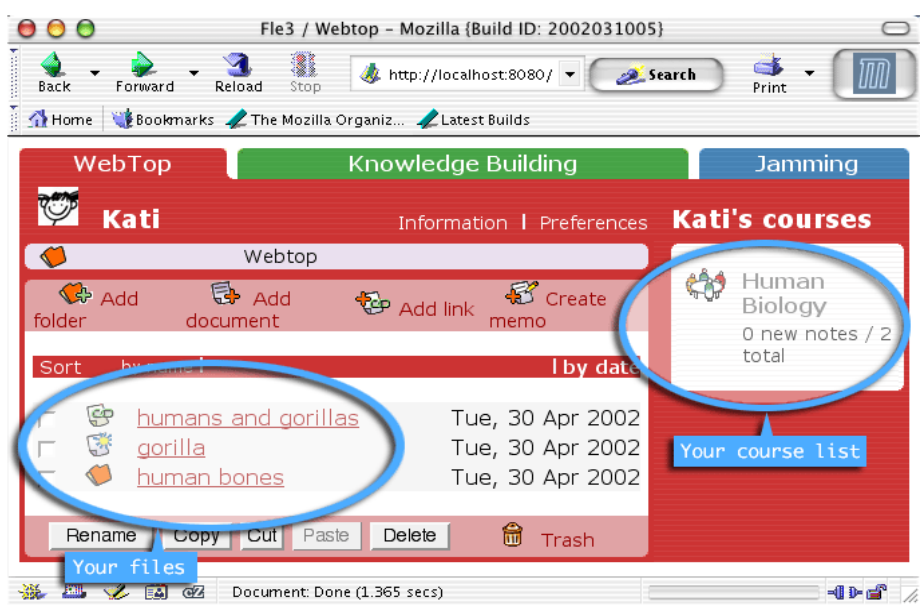

Figure 2: Fle3 webTop screen capture

With Fle3 Knowledge Building tool groups may carry out knowledge building dialogues, theory building and debates by storing their thoughts into a shared database. As you can see in Figure 3, in the Knowledge Building study group may use Knowledge Types to scaffold and structure their dialogues. The Knowledge Type sets are fully editable and one may export and import them from one Fle3 to another. Fle3 comes with two default Knowledge Type sets: (1) Progressive Inquiry, and (2) Design Thinking.

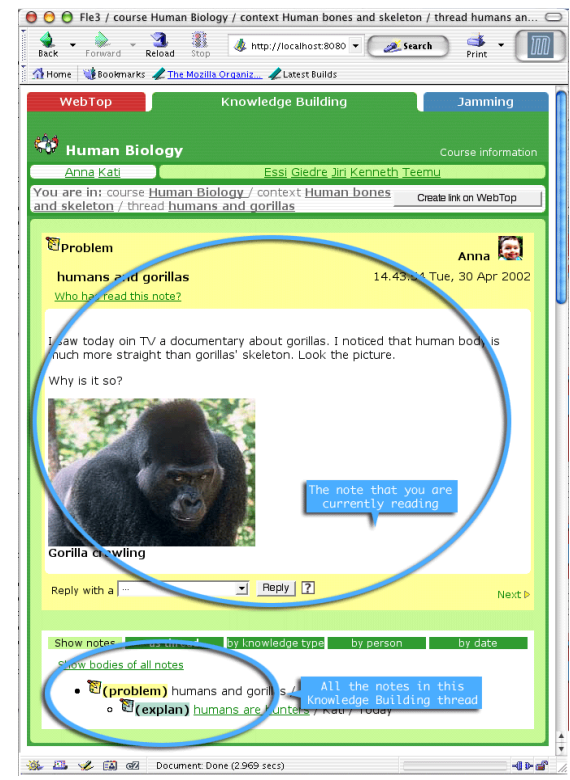

Figure 3: Fle3 Knowledge Building tool - a screen capture

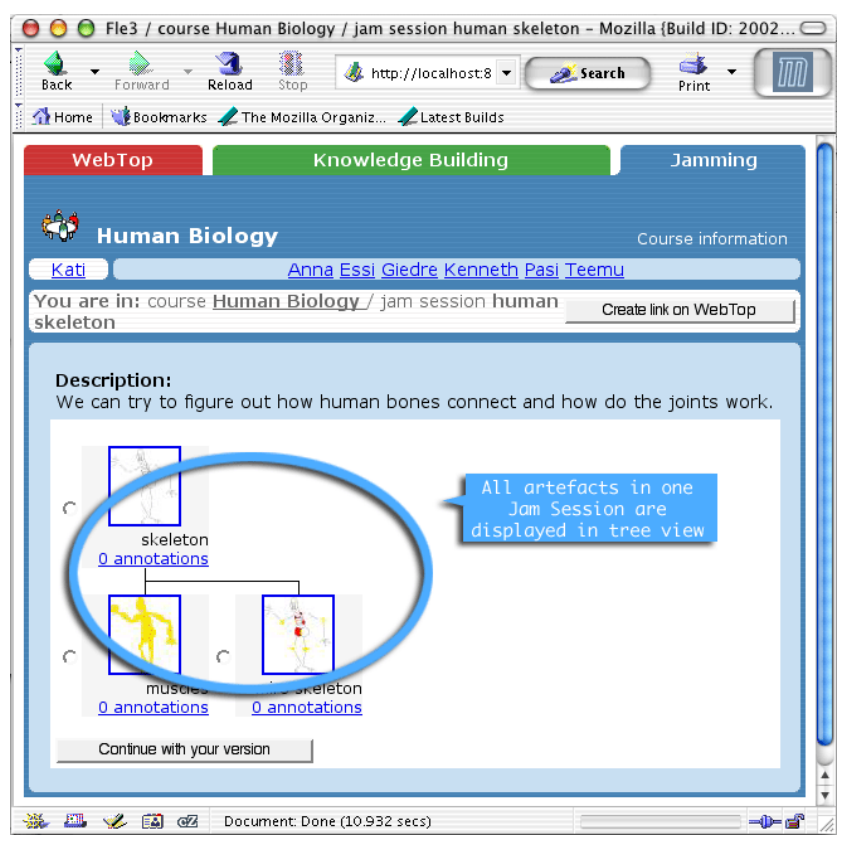

Figure 4: Fle3 Jamming tool screen capture

Fle3 Jamming tool, shown in Figure 4, is a shared space for collaborative construction of digital artifacts (pictures, text, audio, video). A study group may work together with some digital artifacts by simply uploading and downloading files. Versions are tracked automatically and different versions are displayed graphically. Jamming can be used for many kind of collaborative work requiring versioning. 
For teachers and administrators Fle 3 offers tools to manage users and courses / study projects. The administrator may also export and import courses or the full content of Fle3 database in XML format (compatible with the Educational Modeling Language - EML). Access to common users is forbidden for this instrument.

\section{FLE3 Scenario: In a Classroom}

\section{Planning a Study Project}

Two teachers in a secondary school decide to carry out a study project with the classes they are both teaching together, on the production and use of solar energy. One teacher is a science teacher and the other teaches history, economics and social sciences. Together the teachers plan the major phases of the project, search for materials and discuss what are the main concepts, ideas, and skills they want their students to master by the end of the project. To enrich the students learning process the teachers invite two parents to join the online class. One parent is a locally known Green activist that supports alternative energy sources whereas the other parent is working as a researcher in a power company, maintaining nuclear power stations.

\section{Introducing FLE3 for the Participants}

Once the study period starts the teachers give a tour of Fle 3 to the students and explain what kinds of modules, tools and materials are available. Furthermore the teachers explain to the students how the work is supposed to progress in Fle3, and remind them to be active producers of their own study problems, explanations and deeper knowledge found from different sources.

For the participating parents the teachers explain that their role is mainly to act as external experts, from whom students may get scientific information and references to information sources.

The study group starts the work in Fle3's Knowledge Building module by presenting questions and problems related to solar energy. Some of the problems presented in the first stage are such as "why all the roofs of all houses are not covered with solar panels to gain as much solar power as possible?"

Students also present their own explanation and prior understanding of the topic. For instance, a student's own explanation of the previous problem could be: "there are not enough factories to produce all the needed solar panels". After several hours of working with the Knowledge Building students are divided into teams. The teams define for themselves their inquiry tasks and goals.

In order to find scientific knowledge on solar power and the economics of energy, students use their school books and books from the library. Students also have access to several article databases on the Internet and the expert parents offer them a lot of new information. Some of the groups want to try some experiments, so they decide to use the school's science lab and some simulation software available in the classroom computers.

For instance one group does a comparative study on the costs of the production and use of solar energy compared to nuclear energy. As a primary source of their study, they use case studies found from the Internet. At the end of the project the groups present the progress of their work to others and publish it in the form of a study report and poster. The posters are presented in a closing conference organized at the school. At the end of the project all the works are available at the school's digital library on the Internet. 


\section{FLE3 Scenario: In a Blended Learning Project}

\section{Students' Own Initiative to Start a Project}

Three students coming from Bangalore, Johannesburg and Helsinki meet in the queue to the new Bibliotheca Alexandrina in Egypt. While waiting to get into the library building they chat about their experiences in Egypt. All of them have noticed that the air quality in Cairo is not very good. On the other hand all admit that it is not that good in their home towns either. The engineering student from Bangalore has just read about different new techniques and materials for filtering air pollution. The business management student from Johannesburg, who drives a scooter himself, is wondering why there are no motorcycle helmets where these kinds of filters are attached. The industrial designer student points out that it would be better to filter the air earlier than in front of people's mouths, but still agrees that the protection device could also protect people from pollution. After visiting the library the students exchange and share e-mail addresses and disappears into the bazaars of Alexandria and Cairo.

\section{Forming a Group}

A month later the student from Bangalore writes an email to the students he met in Egypt. He proposes that they could make a study project about a filtering system for motorcycle helmets.

The student from Johannesburg is very interested in the idea but definitely wants to have his friend who's studying environmental politics to take part in the project, as well. The industrial designer student from Helsinki is at first very skeptical and wonders if they will ever get any credits from the work. Finally he goes and introduces the study project idea for his professor who thinks it is a brilliant idea, and wants to be the tutor of the study project. To strengthen the team the student from Bangalore proposes that his sister, who uses a motorcycle daily to go shopping, could also take part in the team. The students believe that the sister is able to contribute with relevant information based on her experience of using a helmet. Before starting the project the students still make sure that they can compensate some studies in their study programs with this study project.

\section{Design Process in Fle3}

To start working in the study project the student in Bangalore sets up the Fle3 server. He invites all the participants to the server and they start to have a general discussion in Fle's Knowledge Building module. In the first stage of the project all the participants introduced themselves and get familiar with each other. In the second stage the participants collect information related to filtering technologies, motorcycle helmets, city life and air pollution in big cities and share their findings in Fle3. In the third stage of the project all the team members define the design challenges from users, engineering, design, manufacturing, and business points of view. The process moves on by presenting different design ideas and evaluating them. After five weeks of intensive work in the Fle3 Knowledge Building, the group has an initial concept idea for a helmet with a filter. To elaborate the idea and to put it in more concrete form, they move to work in Jamming. One of the students makes a draft sketch and blueprint of the design, to start the jam session. The members of the team provide different variations that derived from that starting point. 


\section{Educational and Teaching Effects}

\section{Student-centered Collaborative Production of Knowledge and Design Artifacts}

Fle3 software is based on the concept of a 'Future Learning Environment' developed since 1998 by University of Art and Design Media Lab in cooperation with the Center for Research on Networked Learning and Knowledge Building, Department of Psychology at the University of Helsinki.

The term 'Future Learning Environments' is a loose conception of learning which differs from traditional content, teacher, and didactic-based teaching by emphasizing meta-cognitive, problem solving and cooperation skills. The concept stresses student centered collaborative activities aiming to the production of knowledge and design artifacts by embedding meaningful tools and involving the use of information and communication technology (network computers and mobile devices) in the learning process.

\section{New Ways of Working and New Kind of Curriculum Thinking}

The theoretical background of the 'Future Learning Environment' concept is located in social constructivist theory that sees learning as a participation in social processes of knowledge construction.

Future Learning Environment should not be understood only as Fle3 software. The whole concept includes certain pedagogical thinking, hypothetical use cases and situations where Fle 3 software could be useful. The role of Fle3 software is to be the learning tool of the 'Future Learning Environment'. This means that the 'Future Learning Environment' requires much more than Fle3 software. Traditional school communities utilizing a teacher-centered approach, with 45-minute lessons and strict division of school subjects must carry out organizational changes, such as new ways of working, new kinds of scheduling and new kinds of curriculum thinking in order to become 'Future Learning Environments'.

\section{The Italian Scenario}

It is interesting to note that many relevant investigations have been carried out in order to verify and certify online formation. Some organizations, in particular, have performed studies in this field: the CERFAD Committee (Certificazione dei materiali e dei servizi per la Formazione a Distanza) supported by Regione Emilia Romagna; project IPERION (Servizi Telematici per la formazione continua e la sua certificazione) as part of the initiative called Adapt and funded by Ministero del Lavoro e della Commissione, European Community; the model developed by the interplanning group NetEnterprise-Andromeda, coordinated by Cefal in collaboration with Department of Electronics, Information Technology and Systems, University of Bologna; the local research Unity, University of Palermo; the Open Trainer project, supported by partnerships such as the Department of Educational Sciences, University of Padova.

\section{Fle3 is a Tool for Group Centered Work}

In the field of learning technology solutions Fle3 has very specific aims. The research group hope that Fle 3 will be useful in constructive and inquiry-like learning processes. The group knows that, for traditional teachers, concentrating on instruction and didactic-based training, Fle 3 might not be the right tool. Fle3 does not lend itself easily to 'material based learning', where obligatory course material is delivered and then questioned. Neither does Fle3 offer much support for 
teacher-centered models, where the teacher tells learners exactly what to do and when to do it. Fle 3 is a good tool for group-centered work that concentrates on creating and developing expressions of knowledge (i.e. knowledge artifacts). Fle3 is a software for computer supported collaborative learning (CSCL) taking place in a 'Future Learning Environment'.

\section{The Actors (Roles) In the Didactic Environment}

As to technological and educational solutions, Fle3 has a specific goal. The group thinks of Fle3 as a useful tool for a constructive learning process, as well as research fields. The research group also aware that Fle3 is not the right tool for "traditional" teachers. Fle3 cannot be adapted to standard, traditional materials, the latter being simply provided and verified. Similarly, Fle3 does not provide an useful contribution to teacher-centered approaches (teachers tells what to do, and when). Fle3 is a valid tool for knowledge-creation development workgroups. Fle 3 is a CSCL (Computer Supported Collaborative Learning) software developed for a "Future Learning Environment".

\section{The Educational Platform: Defined Roles}

In the Constructivist teaching methodology and the situationist perspective, the teaching environment includes not only technological tools but also the cultural, social, psychological and affective scenarios behind every participant, as attitudes, moods, participations, suggestions, aids are negotiated and shared.

A learning environment is determined (Salomon, Perkins, \& Globerson, 1991) by a series of conditioning occurrences: the physical space or the set of participants (even in a distant environment) which interact, as to fixed behaviours, rules and bonds, operating (shared) activities, objects to be observed, manipulation of reading activities, relations established among participants, the atmosphere created within the group, self-expectations, mental efforts in learning processes turned to sharing activities and negotiation.

The new theoretical learning frame, represented by social-constructivist theories of thought, that is knowledge formed through interaction and learning that act as the interpretation of personal natural experiences (Resnick, Levine, \& Teasley, 1991), or learning as a participation process (Lave \& Wenger, 1991) and a cognitive apprenticeship in an active community (Collins, Brown, \& Newman., 1989), suggest a learning method which has to be supported both by teaching/learning relationships (teachers, tutors, coaching, mentoring) and a negotiation of meanings, in which listening and participating act as major roles.

Interaction becomes a basic educational requisite only if teachers (Walker, Saarenkunnas, Kuure, \& Taalas, 2000) become ethnographers, developing work experiences aimed at promoting listening activities and research perspectives among participants within the activities of the studying process.

A self-regulated and active methodology has been the basic guide for the research planning's approach. The group's knowledge is self-built and shared (Baldassarre \& Arpino, 2003, 2004a, 2004b).

By default there are three different categories of users in an Fle3 system: fle admin, staff and user. Fle admin is the most powerful and can access all functions within the Fle 3 system. The staff user is a bit more restricted and cannot administrate an Fle3 system itself, but can create and manage courses, students and so forth. Finally user is a restricted user who can take part in courses, but can't create courses or new users (nor remove existing ones). In most cases students are defined in the system as users and teachers hold the staff users' rights. The staff user account 
can also be given to a secretary of the department and she will be the person, responsible for giving user accounts, for including users to courses and managing courses etc. Additionally each user gets a role within every course. On a particular course a user can be a 'teacher', 'tutor' or 'student'. Each level has less access rights for that course only. As an example you might be a fle administrator and still be defined as a 'student' on a particular course. Additionally somebody from the user class might be a teacher on one course and have more rights to manage that course (for that course only).

The multi-user management is fully integrated with other modules of the portal (Zope + Plone): this is because all products are based on same database management system ZDBMS (Zope Data Base Management System).

\section{Future Developments}

\section{FLE3 becomes FLE5}

The development team is in contact with Helsinki University (that began fle development and lead the releases roadmap) to test, and develop new version of Fle which will be probably called "Fle5" (fle3 + 2.0 = fle5). FLE5 is built on top of the "Kala framework". It aims at beign a reimplementation of FLE3. The main design changes deal with the transition from DTML to ZPT (Zope Page Templates), the integration of "ImaNote" into knowledge building and jamming views modules, and transition from table-based page layout to CSS-based layout. Minor improvements include replacing the state-encapsulating URLs of FLE3 with relatively clean and intuitive plaintext URLs and streamlining the management interface by combining the courses and users management tabs. An added layer of Python Script files has been added for interfacing with the new modules in FLE5 to keep the interfaces of the Python modules cleaner. The previous Kala style of interfaces which operate directly with REQUEST objects is somewhat opaque and makes unit testing difficult.

\section{Integration between Fle and LeMill}

New publishing methods require new approach to traditional copyright laws: all resources are freely usable by anyone in any context (we can imagine Youtube videos or Slideshare slides). All the content in LeMill platform is released under Creative Commons Attribution-ShareAlike 2.5

What are the success factors and obstacles for collaborative authoring of learning resources by communities of practice? What are the emerging patterns in social software that support collaborative authoring of learning resources?

LeMill is a web community for finding, authoring and sharing open and free learning resources. Its main target groups are teachers and learning content authors, but anyone is free to join. It's an Open Source server software. All learning resources in LeMill must render properly in modern web browsers. There are two kinds of content in LeMill: media pieces and learning resources. A media piece can be a single image, short audio file, or short video clip. A media piece is something that is probably not very useful in such a learning situation but can be used as part of a larger resource. Learning resource is a larger unit of content. For instance a learning resource can be the complete lesson material used in a course. The idea is that you can build learning resources from the media pieces.

Integration bewteen Fle and LeMill is the next step for improving platform features. Users will easly access to all LeMill contents, directly from Fle environment. In the future, you could imag- 
ine a system that provides personalized set of learning contents for each user, depending on his own skill level.

\section{References}

Baldassarre, V. A., \& Arpino, O. (2003). Metodi e tecniche della progettazione e della formazione a distanza, Modulo Profad per "Formatrici a distanza". Università di Bari.

Baldassarre, V. A., \& Arpino O. (2004a). Processi formativi, scienze cognitive e teorie dei sistemi complessi, metodologie sperimentali nei processi formativi, Modulo Profad per "Formatrici a distanza”. Università di Bari.

Baldassarre V. A., \& Arpino, O. (2004b). Verso un modello integrato di OdeL. Indicatori e criteri di qualità, Napoli: Tecnodid.

Collins, A., Brown, J. S., \& Newman, S. E. (1989). Cognitive apprenticeship: teaching the crafts of reading, writing and mathematics. In L. B. Resnick (Ed.), Knowing, learning, and instruction: Essays in honor of Robert Glaser. Hillsdale, NJ: Lawrence Erlbaum Associates.

Convertini, V. N., Albanese, D., Marengo, A., Marengo, V. \& Scalera, M. (2006). The OSEL taxonomy for the classification of learning objects. Interdisciplinary Journal of Knowledge and Learning Objects, 2, 125-138. Retrieved from http://ijello.org/Volume2/v2p125-138Convertini.pdf

Lave, J., \& Wenger, E. (1991). Situated learning: Legitimate peripheral participation. Cambridge: Cambridge University Press.

Marengo, A., Scalera, M., Convertini, N., \& Albanese, A. D. (2007). Integrating systems to enhance learning environments in academia - Case study at University of Bari. Proceedings of Information Technology Interfaces, 2007 (ITI 2007) 29th International Conference.

Resnick, L. B., Levine, J. M., \& Teasley, S. D. (Eds.). (1991). Perspectives on socially shared cognition. Washington, DC: American Psychological Association.

Salomon, G., Perkins, D., \& Globerson, T. (1991). Partners in cognition: Extending human intelligence with intelligent technologies. Educational Researcher, 20(3), 2-9.

Walker, R., Saarenkunnas, M., Kuure, L., \& Taalas, P. (2000). Information and communications technology. Retrieved from www.ict4lt.org/it/it $\bmod 2-3 . h t m \# 5$

\section{Biographies}

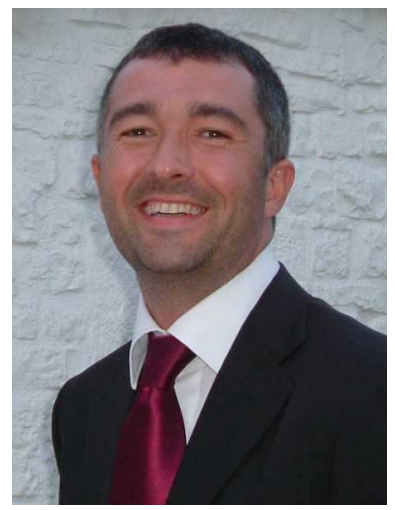

Agostino Marengo, Faculty of Economics, University of Bari Italy. My research activity, as Assistant Professor in Faculty of Economics at University of Bari, takes place primarily on didactic methodologies implemented by the use of ICT tools, particularly the development of e-learning web-based platforms that compete to introduce the technologies of distance learning in traditional institutional campus courses and activities.

As coordinator of OSEL (Open Source e-learning research project, http://www.osel.it), currently my research plan is to create a database of Open Source LCMSs in order to choose and compare them. The research group is actually involved in usability, accessibility and quality evaluation of LMS (Learning Management Systems) and CMS

(Content Management Systems) with a special goal to evaluate Open Source e-learning platforms. Website: http://www.agostinomarengo.it. Skype: agomare. 


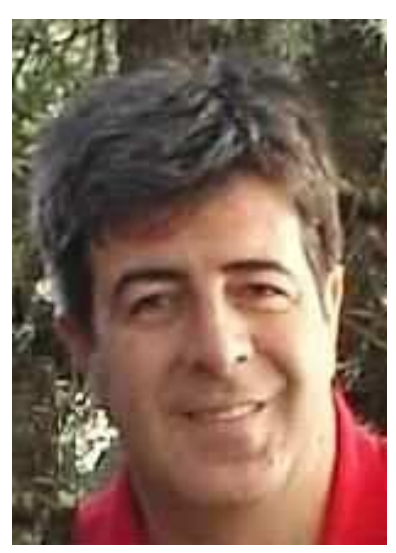

Michele Baldassarre, Faculty of Education Science, University of Bari - Italy. Michele Baldassarre is a researcher at the University of Bari, where he teaches design and sperimentation of multimedia environments for education and elearning. He is the director of $\mathrm{CO}-$ MEDUDIDA (communication - education - didactic), he is professor in the School of Specialization SSIS. It holds Master in Management of technological innovation. The latest publications: e-labor@zioni formative in rete, 2006, Dai dati empirici alla valutazione, 2006 e L'identità del laboratorio nel vissuto degli studenti, 2006.

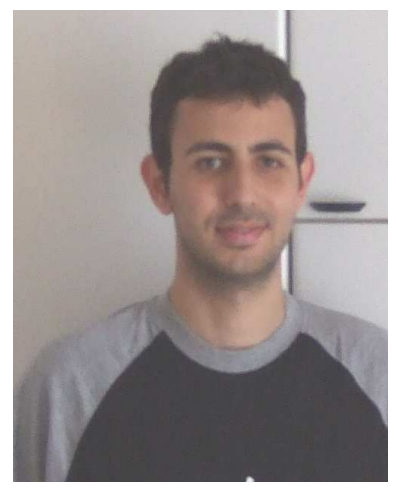

\section{Alessandro Pagano, Faculty of Economics, Thesis Student, Uni-} versity of Bari - Italy. Alessandro Pagano is a student at the University of Bari, faculty of Economy. He's near to graduate and his thesis work is "implementation and sperimentation of an Open Source elearning portal". He is a researcher for the "research $60 \%$ " focused on "planning methods and implementation of didactic models and artifacts, focused on learner and focused on knowledge construction communities. He is teaching at the distance learning post graduate course "Comunicazione Educativa e Didattica" at University of Bari. He is a LUGBari member (Linux User Group). He is an Open Source philosophy supporter. Latest publications: Progettazione e sperimentazione di un ambiente multimediale per la formazione modulare e flessibile (A. Andronico, T. Roselli, V. Rossano, DIDAMATICA 2008). 